\title{
A Novel Newton-Raphson-Based Searching Method for the MTPA Control of PMaSynRM Considering Magnetic and Cross Saturation
}

\author{
Shuo Wang ${ }^{1,2}$, Michele Degano ${ }^{2,3}$, Jinsong Kang ${ }^{1}$, Alessandro Galassini ${ }^{2}$ and Chris Gerada ${ }^{2,3}$
}

\begin{abstract}
Maximum torque per ampere control (MTPA) takes full advantage of the reluctance torque aiming at the minimum copper loss, which can increase the torque output under the minimum current conditions. The traditional MTPA method makes use of equations with constant inductance values which are implemented as look-up tables. However, the inductances of the motor present both magnetic saturation and cross-saturation characteristics. Those parameters are changing depending on the operating point. This paper presents a novel MTPA control strategy of permanent-magnet assisted synchronous reluctance motor (PMaSynRM) implementing a Newton-Raphson-Based Searching Method for improving the control accuracy for optimal current reference. The proposed method eliminates the need of fitting operations due to the nonlinearity of the MTPA formulation and takes the inductance variation, due to magnetic saturation, into account. Finally, the effectiveness of the proposed method is verified by means of Matlab/Simulink simulations.
\end{abstract}

Index Terms-PM assisted Reluctance Motor, MTPA control, Newton-Raphson Algorithm, Magnetic Saturation, CrossSaturation.

\section{INTRODUCTION}

$\mathrm{T}$ he PMaSynRM can be considered as a synchronous reluctance machine with permanent magnets embedded inside the rotor core. Its behaviour is depending on the permanent magnets (PMs) distribution, type (ferrite or rareearth material) and dimensions. These machines are generally presenting high saliency ratio and relatively low flux linkage, when compared to interior permanent magnet synchronous machine. With respect to the pure synchronous reluctance machine (SynRM), PMaSynRM machines provide better torque, higher power factor and extended speed range capability [1]-[4].

Since the permanent magnets are embedded inside the rotor barriers, the $d$-axis inductance in the synchronous reference frame is considerably different with respect to the $q$-axis inductance. This difference contributes to the additional torque that is generated as the reluctance torque. Therefore, the generated torque consists of two components defined as the permanent magnet torque and the reluctance torque. The former is proportional to the $d$-axis current, and the reluctance torque is related to the product of the $d$-axis current with the $q$-axis current. A specific torque can be generated by various current vectors in the dq-axis reference

S. Wang ${ }^{1}$ and J. Kang ${ }^{1}$ are with the College of Electronic and Information Engineering, Tongji University, Shanghai, China.

M. Degano ${ }^{2}$, S. Wang ${ }^{2}$, A. Galassini ${ }^{2}$ and Chris Gerada ${ }^{2}$ are with the Power Electronics, Machines and Control Group, the University of Nottingham, Nottingham, UK. M. Degano ${ }^{3}$ and C. Gerada ${ }^{3}$ are also with the PEMC Group the University of Nottingham Ningbo China, Ningbo, China. (e-mail: michele.degano@nottingham.ac.uk). frame. Among all the combinations of the current vectors, the maximum torque per ampere (MTPA) trajectory is built on current vectors with minimum magnitude, which guarantees reduced copper loss. In other words, the MTPA can also be considered as the maximum torque with a constant current magnitude.

There are several works in literature discussing the control within MTPA operations. The techniques proposed can be divided into four main categories:

1) simple mathematical calculations of MTPA using the magnetic model of the motor without considering the magnetic saturation;

2) MTPA point tracking by means of additional high frequency injection;

3) minimum current operation using a searching algorithm;

4) parameter compensation by LUT or identification method.

The first methods in [5], a Lagrangian multiplier function is commonly used to minimize the torque equation with respect to the current magnitude. The method takes advantage of the parameters of the motor, such as inductance, flux linkage, etc., to obtain the optimal reference value of the current through MTPA nonlinear formula operation. However, depending on the operating conditions, there are some changes in the parameters of the motor, especially the inductance values. This variation is due to the influence of the magnetic saturation and cross-saturation phenomena [6][7]. The traditional MTPA methods, using constant inductance values, lead to current reference different from the optimal one, which results in higher copper loss and lower efficiency. These approaches are sensitive to parameter variation.

The second methods are based on high frequency harmonic injection of current [8] or voltage [9] to the machine terminals. The MTPA points can be detected from the torque or speed response by a series of signal processing [8]. The key point is that the high-frequency signal can be injected into the space vector directly or indirectly. Then, the MTPA operational point is analysed by the variation in the speed measurement or stator current magnitude. However, the performance of these methods is limited by the current control bandwidth, of the injected current signals. The motor torque and current ripples are also increased.

The third method uses the automatic search method as presented in [10]-[15]. One of the simplest search methods is the exhaustive method, which requires several operating points and performs a large range of operations and comparisons to find the extreme values, and therefore increases computation burdens for the controller. In [10], authors are searching for the MTPA operating point by 
modulating the current phase angle and observing the variation in the power command, therefore the tracking algorithm is suitable only for slow dynamic applications. In [11], optimal dq-current step adjustments are calculated from these approximate voltage/torque increment lines with differential approach. Some researchers present Hill-climbing method in [12] or gradient descent method in [13], although the method shows good convergence, the derivative of the dynamic inductances with respect to the current with cross saturation is neglected for the simplicity of calculation. These methods do not achieve maximum accuracy.

In the fourth method, parameter compensation for variable inductance are used in [9][14]. Lookup tables are widely used for magnetic saturation. However, lookup tables tend to be huge because it is necessary to create separate MTPA tables on the basis of inductance variation. To tune those parameters time-consuming experimental measurements are often required. In [14], a fitting model for the nonlinear flux linkage is proposed, approximate precision needs to be further improved. Other works are proposing parameter identification methods to adjust the inductance parameters [15], which undoubtedly increases the complexity of the algorithm and the convergence rate for these parameter identification methods.

This paper proposes a novel Newton-Raphson based searching strategy, in combination with the third and the fourth methods. The influence of magnetic saturation and cross saturation into consideration is compensated by LUT. Firstly, the mathematical model of the motor based on nonlinear flux linkage is reconstructed. By revising the traditional Lagrange multiplier equation considering magnetic saturation and cross-saturation, the second-order Newton-Raphson method is used as an automatic search algorithm aiming at the minimum copper loss. The results show a more accurate solution compared with constant inductance, the Newton-Raphson algorithm demonstrates the automatic search for the optimal dq-axis reference current with only few iterations with fast convergence and good accuracy for any operating conditions.

\section{ANALYSIS OF PMASYNRM MODEL AND MTPA OPERATION}

\section{A. PMaSynRM Model}

In Fig. 1 a sketch of the 6 pole PMaSynRM machine considered in this work is presented. In the dq-reference frame, the equations describing the operation of a PMaSynRM can be written as follows:

Voltage equation:

$$
\begin{aligned}
& \left\{\begin{array}{l}
u_{d}=R_{s} i_{d}+\frac{d \psi_{d}}{d t}-\omega_{e} \psi_{q} \\
u_{q}=R_{s} i_{q}+\frac{d \psi_{q}}{d t}+\omega_{e} \psi_{d}
\end{array}\right. \\
& \left\{\begin{array}{l}
\psi_{d}=L_{d} i_{d} \\
\psi_{q}=L_{q} i_{q}-\psi_{f}
\end{array}\right.
\end{aligned}
$$

where, $u_{d}$ and $u_{q}$ are the dq-axis stator voltages; $i_{d}$ and $i_{q}$ are dq-axis current components; $L_{d}$ and $L_{q}$ are the inductance of PMaSynRM along the $\mathrm{d}$ and q-axis, respectively. $R_{s}, \psi_{f}$ and $p$ are the stator resistance, the permanent-magnet flux linkage and the pole pairs, respectively. $\omega_{\mathrm{e}}$ is the electrical pulsation. The torque equation can be described as:

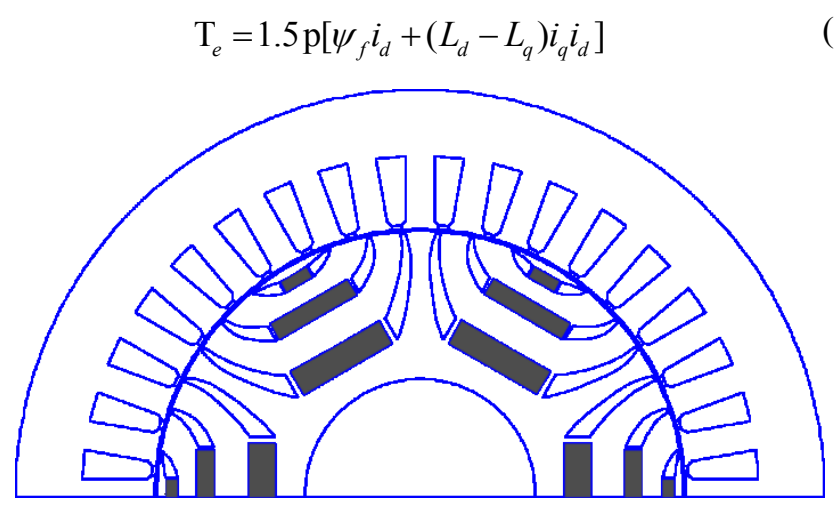

Fig.1: Sketch of the 6 pole PMaSynRM machine.

\section{B. MTPA Analysis}

Among all the control strategies, the MTPA one is the most commonly used [11]-[12]. For a given operating condition, corresponding to a defined torque demand, MTPA control method focuses on the minimum copper losses with maximum torque production.

The MTPA solution is formulated aiming at copper loss minimization problem. The superscript * represents the reference value of the currents in the subsequent description.

$$
\begin{cases}\min & R_{s}\left(i_{d}^{* 2}+i_{q}^{* 2}\right) \\ \text { s.t. } & T_{e}^{*}=1.5 \mathrm{p}\left[\psi_{f} i_{d}^{*}+\left(L_{d}-L_{q}\right) i_{q}^{*} i_{d}^{*}\right]\end{cases}
$$

The Lagrange Multiplier applied for Minimum copper loss can be describes as follows:

$$
\begin{gathered}
H\left(i_{d}^{*}, i_{q}^{*}, \lambda\right)=R_{s}\left(i_{d}^{* 2}+i_{q}^{* 2}\right)+\lambda\left[T_{e}^{*}-\psi_{f} i_{d}^{*}-\left(L_{d}-L_{q}\right) i_{q}^{*} i_{d}^{*}\right] \\
\left\{\begin{array}{l}
\frac{\partial H\left(i_{d}^{*}, i_{q}^{*}, \lambda\right)}{\partial i_{d}}=2 R_{s} i_{d}^{*}-\lambda \frac{3}{2} \mathrm{p}\left(\psi_{f}+\left(L_{d}-L_{q}\right) i_{q}^{*}\right)=0 \\
\frac{\partial H\left(i_{d}^{*}, i_{q}^{*}, \lambda\right)}{\partial i_{q}}=2 R_{s} i_{q}^{*}-\lambda \frac{3}{2} \mathrm{p}\left(L_{d}-L_{q}\right) i_{d}^{*}=0 \\
\frac{\partial H\left(i_{d}^{*}, i_{q}^{*}, \lambda\right)}{\partial \lambda}=T_{e}-\frac{3}{2} p\left(\psi_{f} i_{d}^{*}+\left(L_{d}-L_{q}\right) i_{d}^{*} i_{q}^{*}\right)=0
\end{array}\right.
\end{gathered}
$$

Solving the first two equations by eliminating the parameter $\lambda$, the relationship for $i_{d}$ and $i_{q}$ can be derived as:

$$
\left(L_{d}-L_{q}\right) i_{d}^{* 2}-\left(L_{d}-L_{q}\right) i_{q}^{* 2}-\psi_{f} i_{q}^{*}=0
$$

It is worth to observe that the MTPA mathematical relationship represented by (7) is a nonlinear function of a hyperbolic relationship, as shown in Fig. 2.

The following are the issues related to MTPA control:

1) MTPA is a nonlinear equation with a root operation, which is quite complex to solve directly. The traditional MTPA control method with a constant inductance to construct MTPA curve is not accurate.

2) Traditional motor parameters such as $L_{\mathrm{d}}, L_{\mathrm{q}}$ and $\Psi_{\mathrm{f}}$ are considered constant and independent of the motor operating point, which means that the effects of saturation and cross saturation on inductances are neglected. However, 
in the real operating conditions, these parameters are changing with the input current [7][8][13][14].

3) The look-up table method is commonly used and these lookup tables tend to be huge with large memory because it is necessary to create separate MTPA tables on the basis of inductance variation. The estimation of MTPA with the parameters variation requires a considerable amount of fitting work and it is very time consuming.

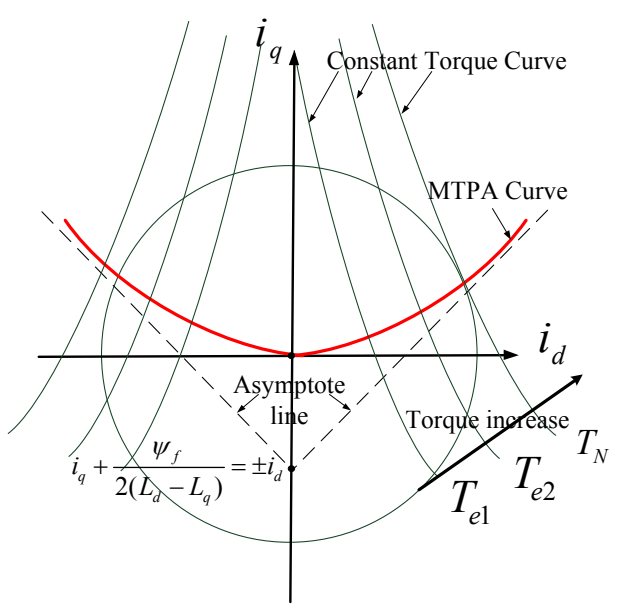

Fig.2: MTPA curve in dq-axis current plane.

\section{Magnetic model of the motor}

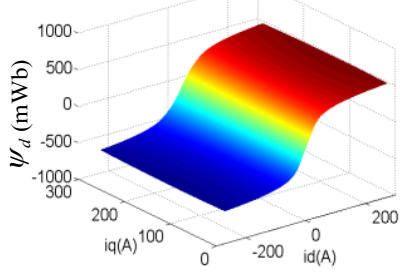

(a)

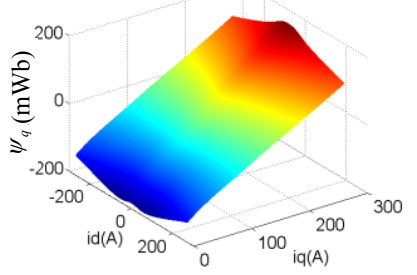

(b)
Fig.3: the magnetic saturation and cross saturation phenomenon (a) d-axis flux (b) q-axis flux.

Considering the saturation of the magnetic circuit for the inductance, the $\mathrm{d}$-axis and $\mathrm{q}$-axis inductances are affected by the dq-axis current, so that the flux linkage cannot be expressed as a linear equation or a constant inductance under a large current or a heavy load. For a PMaSynRM, the dqaxis flux linkage exhibits different magnetic saturation characteristics for the dq-axis current. The d-axis flux linkage is saturating faster with respect to the q-axis flux linkage, which presents a more linear characteristic, as shown in the Fig. 3. For the d-axis flux linkage, under the condition of low current loading, the d-axis flux linkage shows a linear relationship under $40 \mathrm{~A}$ current.

On the other hand, as the q-axis current increases, d-axis flux linkage will also increase. This phenomenon is known as cross-saturation and leads to more complex equations, since it is very difficult to give an analytic solution of crosssaturation directly. Considering the magnetic saturation and cross-saturation phenomenon, the direct-axis flux linkage and cross-axis flux linkage can be expressed as a non-linear function of the inductance with the dq axis currents.

$$
\psi_{d}\left(i_{d}, i_{q}\right)=L_{d}\left(i_{d}, i_{q}\right) i_{d}
$$

$$
\psi_{q}\left(i_{d}, i_{q}\right)=L_{q}\left(i_{d}, i_{q}\right) i_{q}-\psi_{f}\left(i_{d}, 0\right)
$$

Where $\Psi_{\mathrm{d}}$ and $\Psi_{\mathrm{q}}$ are the dq axis flux linkages under the influence of magnetic saturation, $L_{\mathrm{d}}$ and $L_{\mathrm{q}}$ are the inductances varying with dq axis currents, and $\Psi_{\mathrm{f}}$ is the permanent magnet flux linkage influenced by the $\mathrm{d}$-axis current.

The magnetic mathematical model for a PMaSynRM machine can be rewritten as:

$$
\left\{\begin{array}{l}
u_{d}=R_{s} i_{d}+\frac{d \psi_{d}\left(i_{d}, i_{q}\right)}{d t}-\omega_{e} \psi_{q}\left(i_{d}, i_{q}\right) \\
u_{q}=R_{s} i_{q}+\frac{d \psi_{q}\left(i_{d}, i_{q}\right)}{d t}+\omega_{e} \psi_{d}\left(i_{d}, i_{q}\right) \\
T_{e}=\frac{3}{2} \mathrm{p}\left[\psi_{d}\left(i_{d}, i_{q}\right) i_{q}-\psi_{q}\left(i_{d}, i_{q}\right) i_{d}\right] \\
=\frac{3}{2} p\left[\psi_{f} i_{d}+\left(L_{d}\left(i_{d}, i_{q}\right)-L_{q}\left(i_{d}, i_{q}\right)\right) i_{d} i_{q}\right]
\end{array}\right.
$$

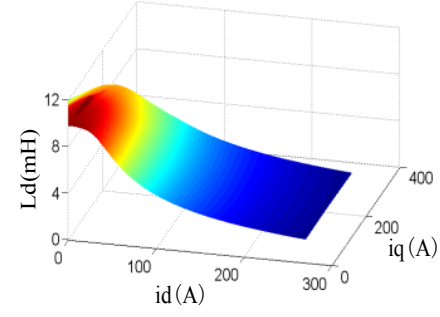

(a) (b)

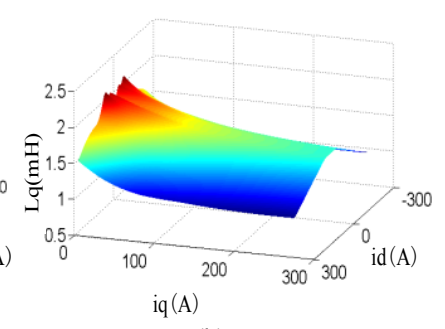

Fig. 4: the 3-D plots of $L_{\mathrm{d}}$ and $L_{\mathrm{q}}$ (a) d-axis inductance (b) q-axis inductance

Fig. 4 shows the 3 -D plots of $L_{\mathrm{d}}$ and $L_{\mathrm{q}}$ inductances as a function of the dq-axis currents, determined by means of finite element (FE) simulations. The inductances were computed in the current range, from $-200 \mathrm{~A}$ to $200 \mathrm{~A}$ in the second and first quadrant, respectively. Due to the complexity of the magnetic saturation and cross-saturation equations, in this paper, the two-dimensional look-up table is utilized to find the inductance of the motor with different dq axis current.

\section{The Proposed NEWTON-RAPHSON METHOD FOR MTPA CONTROL}

The second order Newton-Raphson method (abbreviated to N-R searching method) is a fast convergence procedure used to solve nonlinear equations to obtain the optimal result for generic $\mathrm{x}$ and $\mathrm{y}$ variables, with the condition $f(x, y)=0$ and $g(x, y)=0$. By the recurrence formula, starting the iterative process with an initial value $\mathrm{x}(0)$ and $\mathrm{y}(0)$ as first guess, after a few steps the optimal solutions can be obtained.

To find a value of $x, y$ that satisfies the equation (11)

$$
\left\{\begin{array}{l}
z_{1}=f(x, y)=0 \\
z_{2}=g(x, y)=0
\end{array}\right.
$$

where $f(x, y)$ and $g(x, y)$ are some function, the NewtonRaphson method uses the following formula to get a better estimate of $x_{\mathrm{n}+1}$ and $y_{\mathrm{n}+1}$ from a previous value of $x_{\mathrm{n}}$ and $y_{\mathrm{n}}$.

The formula for (8) should be corrected into Lagrange multiplier equation of formula (12) 


$$
\left\{\begin{aligned}
\frac{\partial H\left(i_{d}^{*}, i_{q}^{*}, \lambda\right)}{\partial i_{d}}= & 2 R_{s} i_{d}^{*}-\lambda \frac{3}{2} \mathrm{p}\left[\left(L_{d}\left(i_{d}, i_{q}\right)-L_{q}\left(i_{d}, i_{q}\right)\right) i_{q}^{*}\right. \\
& \left.+\left(\left.\frac{\partial L_{d}\left(i_{d}, i_{q}\right)}{\partial i_{d}}\right|_{i_{d}^{*}}-\left.\frac{\partial L_{q}\left(i_{d}, i_{q}\right)}{\partial i_{d}}\right|_{i_{d}^{*}}\right) i_{d}^{*} i_{q}^{*}+\psi_{f}\right]=0 \\
\frac{\partial H\left(i_{d}^{*}, i_{q}^{*}, \lambda\right)}{\partial i_{q}}= & 2 R_{s} i_{q}^{*}-\lambda \frac{3}{2} \mathrm{p}\left(\left(L_{d}\left(i_{d}, i_{q}\right)-L_{q}\left(i_{d}, i_{q}\right)\right) i_{d}^{*}\right. \\
& +\left(\left.\frac{\partial L_{d}\left(i_{d}, i_{q}\right)}{\partial i_{q}}\right|_{i_{q}^{*}}-\left.\frac{\partial L_{q}\left(i_{d}, i_{q}\right)}{\partial i_{q}}\right|_{i_{q}^{*}} ^{*} i_{d}^{*} i_{q}^{*}\right)=0 \\
\frac{\partial H\left(i_{d}^{*}, i_{q}^{*}, \lambda\right)}{\partial \lambda}= & T_{e}^{*}-\frac{3}{2} p\left(\psi_{f} i_{d}^{*}+\left(L_{d}\left(i_{d}, i_{q}\right)-L_{q}\left(i_{d}, i_{q}\right)\right) i_{d}^{*} i_{q}^{*}\right)=0
\end{aligned}\right.
$$

The first two equations of formula (12) can be combined to obtain the equation (13).

$$
\left\{\begin{array}{l}
f\left(i_{d}^{*}, i_{q}^{*}\right)=T_{e}^{*}-\frac{3}{2} p\left[\psi_{f} i_{d}^{*}+\left(L_{d}-L_{q}\right) i_{d}^{*} i_{q}^{*}\right] \\
g\left(i_{d}^{*}, i_{q}^{*}\right)=-\psi_{f} i_{q}^{*}+\left(L_{d}-L_{q}\right) i_{d}^{* 2}-\left(L_{d}-L_{q}\right) i_{q}^{* 2}+L_{2} i_{d}^{*} i_{q}^{*}-L_{1} i_{d}^{*} i_{q}^{* 2}
\end{array}\right.
$$

where

$$
L_{1}=\frac{\partial L_{d}}{\partial i_{d}}-\frac{\partial L_{q}}{\partial i_{d}}, \quad L_{2}=\frac{\partial L_{d}}{\partial i_{q}}-\frac{\partial L_{q}}{\partial i_{q}}
$$

The Jacobi matrix of the flux linkage is listed as follows:

$$
J_{L}=\left[\begin{array}{ll}
\frac{\partial L_{d}\left(i_{d}, i_{q}\right)}{\partial i_{d}} & \frac{\partial L_{d}\left(i_{d}, i_{q}\right)}{\partial i_{q}} \\
\frac{\partial L_{q}\left(i_{d}, i_{q}\right)}{\partial i_{d}} & \frac{\partial L_{q}\left(i_{d}, i_{q}\right)}{\partial i_{q}}
\end{array}\right] \stackrel{\text { Marked as symbol }}{\longrightarrow}\left[\begin{array}{ll}
L_{d i d} & L_{d i q} \\
L_{q i d} & L_{q i q}
\end{array}\right]
$$

The Jacobian matrix of (14) can be expressed as (15):

$$
\begin{aligned}
& J=\left[\begin{array}{cc}
\frac{\partial f\left(i_{d}^{*}, i_{q}^{*}\right)}{\partial i_{d}^{*}} & \frac{\partial f\left(i_{d}^{*}, i_{q}^{*}\right)}{\partial i_{q}^{*}} \\
\frac{\partial g\left(i_{d}^{*}, i_{q}^{*}\right)}{\partial i_{d}^{*}} & \frac{\partial g\left(i_{d}^{*}, i_{i}^{*}\right)}{\partial i_{q}^{*}}
\end{array}\right] \stackrel{\text { Marked as symbol }}{\longrightarrow}\left[\begin{array}{cc}
f_{x} & f_{y} \\
g_{x} & g_{y}
\end{array}\right] \\
& =\left[\begin{array}{cc}
-\frac{3}{2} p\left[\left(L_{d}-L_{q}\right) i_{q}^{*}+\psi_{f}\right] & -\frac{3}{2} p\left[\left(L_{d}-L_{q}\right) i_{d}^{*}\right] \\
2\left(L_{d}-L_{q}\right) i_{d}^{*}+2 L_{2} i_{d}^{*} i_{q}^{*}-L_{i} i_{q}^{* 2} & -\psi_{f}+L_{i} i_{d}^{i^{2}}-2\left(L_{d}-L_{q}\right) i_{q}^{*}-2 L_{1} i_{d}^{*} i_{q}^{*} i_{q}^{*}
\end{array}\right]
\end{aligned}
$$

According to the N-R algorithm, the binary function solution obtained by equation can be expressed as an iterative form of equation (16).

$$
\left[\begin{array}{l}
i_{d n+1}^{*} \\
i_{q n+1}^{*}
\end{array}\right]=\left[\begin{array}{l}
i_{d n}^{*} \\
i_{q n}^{*}
\end{array}\right]-J^{-1}\left[\begin{array}{l}
f\left(i_{d n}^{*}, i_{q n}^{*}\right) \\
g\left(i_{d n}^{*}, i_{q n}^{*}\right)
\end{array}\right]
$$

$f_{\mathrm{x}} f_{\mathrm{y}} g_{\mathrm{x}} g_{\mathrm{y}}$ needs to meet the conditions:

$$
g_{x} f_{y}-f_{x} g_{y} \neq 0
$$

Substituting the inverse of the Jacobian matrix into equation (16) yields equation (18):

$$
\left\{\begin{array}{l}
i_{d n+1}^{*}=i_{d n}^{*}+\frac{f\left(i_{d n}^{*}, i_{q n}^{*}\right) g_{y}\left(i_{d n}^{*}, i_{q n}^{*}\right)-g\left(i_{d d}^{*}, i_{q n}^{*}\right) f_{y}\left(i_{d n}^{*}, i_{q n}^{*}\right)}{g_{x}\left(i_{d n}^{*}, i_{q n}^{*}\right) f_{y}\left(i_{d n}^{*}, i_{q n}^{*}\right)-f_{x}^{*}\left(i_{d n}^{*}, i_{q n}^{*}\right) g_{y}\left(i_{d n}^{*}, i_{q n}^{*}\right)} \\
i_{q n+1}^{*}=i_{q n}^{*}+\frac{g\left(i_{d n}^{*}, i_{q n}^{*}\right) f_{x}\left(i_{d n}^{*}, i_{q n}^{*}\right)-f\left(i_{d n}^{*}, i_{q n}^{*}\right) g_{x}\left(i_{d n}^{*}, i_{q n}^{*}\right)}{g_{x}\left(i_{d n}^{*}, i_{q n}^{*}\right) f_{y}\left(i_{d n}^{*}, i_{q n}^{*}\right)-f_{x}\left(i_{d n}^{*}, i_{q n}^{*}\right) g_{y}\left(i_{d n}^{*}, i_{q n}^{*}\right)}
\end{array}\right.
$$

where $x_{n+1}$ and $y_{n+1}$ are the new estimate of $x$ and $y, x_{n}$ and $y_{n}$ are the previous estimate of $x$ and $y$ respectively, $f\left(x_{n}\right.$, $\left.y_{n}\right)$ and $g\left(x_{n}, y_{n}\right)$ are the function evaluated using $x_{n} y_{n}$ (note that $f\left(x_{n}, y_{n}\right) \neq 0$ and $g\left(x_{n}, y_{n}\right) \neq 0$ because $x_{n}$ is not the correct solution), and Jacobi matrix are the partial derivative of $f(x, y)$ and $g(x, y)$ evaluated using $x_{n} y_{n} . n$ is an integer iteration index that starts with 1 . The iterative procedure starts by substituting a first guess into (19) to get a second estimate. This second estimate is then substituted into (19) to get a third estimate. This process is repeated until the geometric distance of two iterations are below a define threshold. Final convergence condition can be defined as:

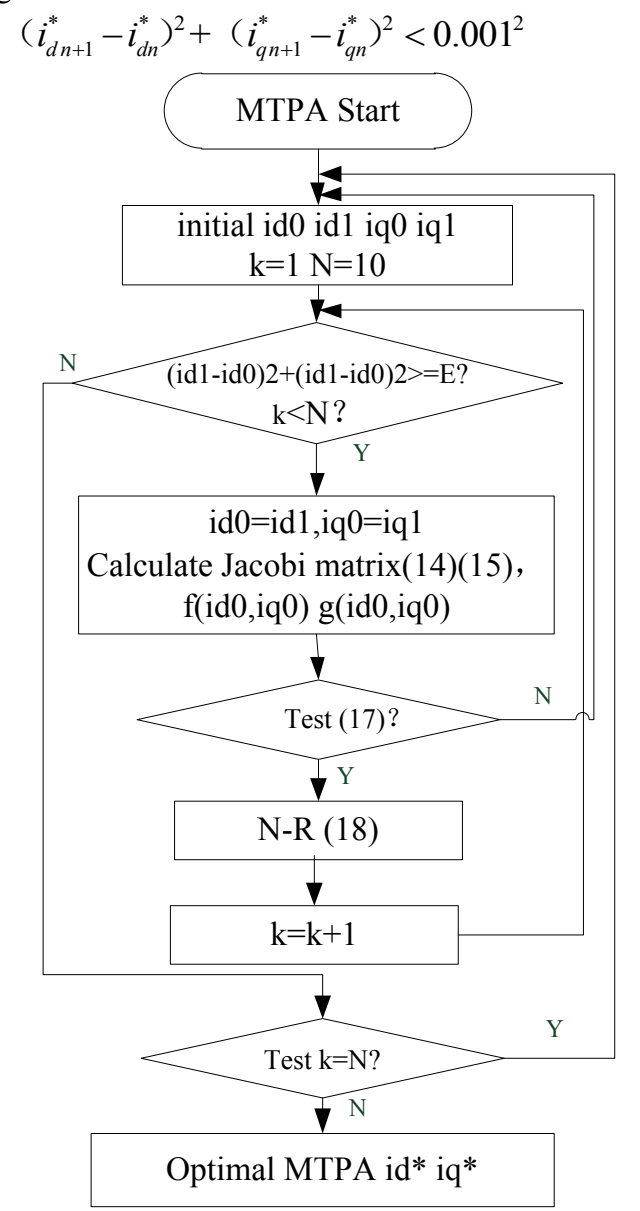

Fig. 5 the Newton-Raphson searching algorithm flow chart

Newton-Raphson based on search method of PMaSynRM flowchart is shown in the Fig.5, initial value is set at first, $\mathrm{k}$ represents the current iteration. $\mathrm{N}$ represents the maximum number of iterations. id1 and iq1 set the initial value in the first quadrant inside the current limit circle within the first iteration of the Jacobian matrix and the initial function value $f\left(i_{\mathrm{d} 0}, i_{\mathrm{q} 0}\right)$ and $g\left(i_{\mathrm{d} 0}, i_{\mathrm{q} 0}\right)$ is used for the N-R iterative algorithm. This is calculated by updating id 1 and iq 1 , repeated iterative updates continue to search, until the iterative error reaches a value below the threshold set. The torque converges to the optimal point rapidly, and the optimal current setting values for the MTPA are obtained.

\section{Simulation Results}

In order to investigate the influence of the initial values on the Newton-Raphson search results, four simulation experiments have been carried out with two different torque and inductance values given. The motor parameters are shown in Table. I. Since the optimal current reference should be limited in the first quadrant, the rated current value is $72.5 \mathrm{~A}$, obtained by the maximum current value under the rated torque 120Nm. Fig. 6 and Fig. 7 depict the iteration 
results from different initial current values. The detailed iteration process with two initial conditions is listed in Table II. The current initial values are set to be $(20 \mathrm{~A}, 60 \mathrm{~A})$ and (40A, 15A), which finally converge to $(53.82 \mathrm{~A}, 45.53 \mathrm{~A})$ in Case I and (7.28A,2.03A) in Case II, respectively. The simulation results show that the proposed N-R search algorithm does not depend on the selected initial value of $\mathrm{id}^{*}$ and iq* and it can cover all the ranges from low torque to rated torque and it has a fast convergence rate with less than 7 iterations for getting the optimal results.

TABLE I SPECIFICATIONS OF THE TARGET PMASYNRM

\begin{tabular}{lc}
\hline \multicolumn{1}{c}{ PARAMETERS } & VALUES \\
\hline Rated power $\mathrm{kW}$ & 37 \\
Max torque $\mathrm{Nm}$ & 126 \\
Rated speed rpm & 2800 \\
Stator resistance $\Omega$ & 0.1334 \\
d-axis inductance $\mathrm{mH}$ & $7.65-9.85$ \\
q-axis inductance $\mathrm{mH}$ & $1.81-2.06$ \\
Pole pairs & 3 \\
Permanent magnetic linkage $\mathrm{Wb}$ & 0.1408 \\
\hline
\end{tabular}

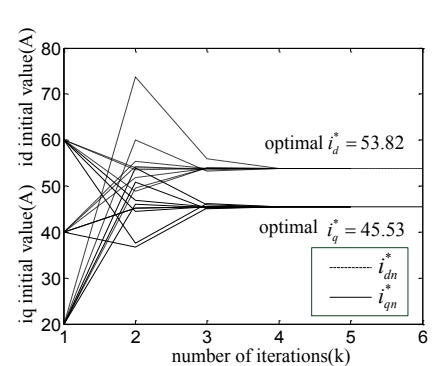

(a)

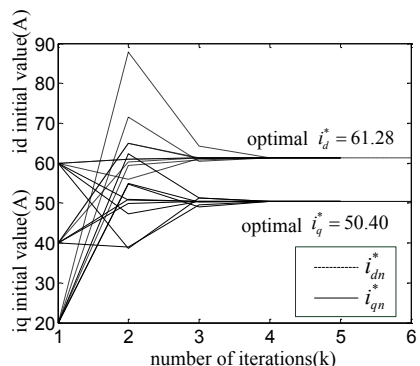

(b)
Fig. 6 the Newton-Raphson searching process with high reference torque (a) $\mathrm{Te}=120 \mathrm{Nm}, \mathrm{Ld}=9.85 \mathrm{mH}, \mathrm{Lq}=2.06 \mathrm{mH}$ (b) $\mathrm{Te}=120 \mathrm{Nm}, \mathrm{Ld}=7.65 \mathrm{mH}, \mathrm{Lq}=1.81 \mathrm{mH}$

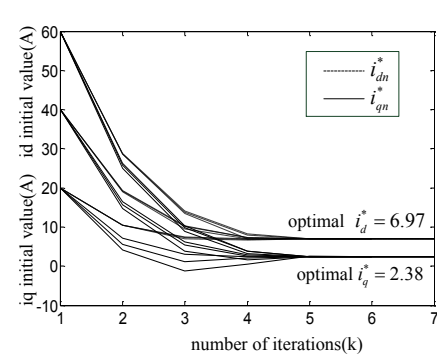

(a)

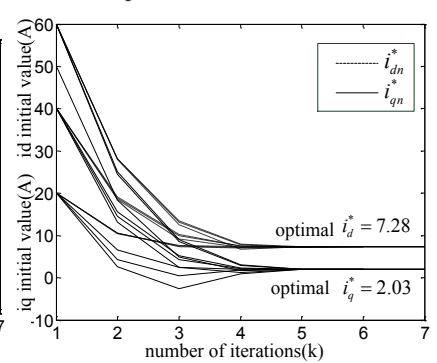

(b)
Fig. 7 the Newton-Raphson searching process with low reference torque (a) $\mathrm{Te}=5 \mathrm{Nm}, \mathrm{Ld}=9.85 \mathrm{mH}, \mathrm{Lq}=2.06 \mathrm{mH}$

(b) $\mathrm{Te}=5 \mathrm{~N} . \mathrm{m}, \mathrm{Ld}=7.65 \mathrm{mH}, \mathrm{Lq}=1.81 \mathrm{mH}$

TABLE II ITERATION PROCESS FOR N-R METHOD

\begin{tabular}{ccc}
\hline \multicolumn{2}{c}{ INITIAL CONDITION } & ITERATION PROCESS \\
\hline Case I & (id0,iq0) & $(20,60) \rightarrow(49.60,37.54) \rightarrow(53.90,46.12)$ \\
$\mathrm{Ld}=9.85 \mathrm{mH}$ & $=(20 \mathrm{~A}, 60 \mathrm{~A})$ & $\rightarrow(53.82,45.54) \rightarrow(53.82,45.53)$ \\
$\mathrm{Lq}=2.06 \mathrm{mH}$ & $($ id0,iq0 $)$ & $(40,15) \rightarrow(51.86,57.70) \rightarrow(53.13,46.08)$ \\
$\mathrm{Te}=120 \mathrm{~N} . \mathrm{m}$ & $=(40 \mathrm{~A}, 15 \mathrm{~A})$ & $\rightarrow(53.81,45.53) \rightarrow(53.82,45.53)$ \\
\hline Case II & $($ id0,iq0 & $(20,60) \rightarrow(10.55,25.13) \rightarrow(7.31,9.07) \rightarrow$ \\
$\mathrm{Ld}=7.65 \mathrm{mH}$ & $=(20 \mathrm{~A}, 60 \mathrm{~A})$ & $(7.04,3.12) \rightarrow(7.26,2.06) \rightarrow(7.28,2.03)$ \\
$\mathrm{Lq}=1.81 \mathrm{mH}$ & $($ id0,iq0 $)$ & $(40,15) \rightarrow(18.39,1.78) \rightarrow(8.85,-0.34) \rightarrow$ \\
$\mathrm{Te}=5 \mathrm{~N} . \mathrm{m}$ & $=(40 \mathrm{~A}, 15 \mathrm{~A})$ & $(7.12,2.04) \rightarrow(7.28,2.03)$ \\
\hline
\end{tabular}

The MTPA trajectory, the constant torque curve and current limit circle over all the operating range are drawn in $\mathrm{dq}$ axis current plane in Fig. 8. The solid lines in the figure show the setting torque with $L_{\mathrm{d}}=9.85 \mathrm{mH}$ and $L_{\mathrm{q}}=2.06 \mathrm{mH}$, and the dotted lines represent the setting torque with $L_{\mathrm{d}}=7.65 \mathrm{mH}$ and $L_{\mathrm{q}}=1.81 \mathrm{mH}$. Variable inductance shows a significant effect on the optimal current trajectory curve of the MTPA, and the constant torque curve will also shift due to the change of inductance parameters.

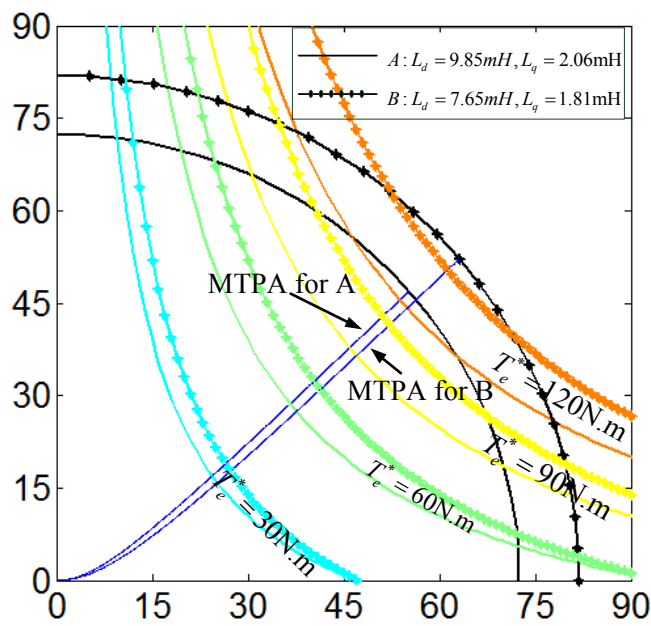

Fig. 8 MTPA curve considering or neglecting magnetic saturation in dq current plane

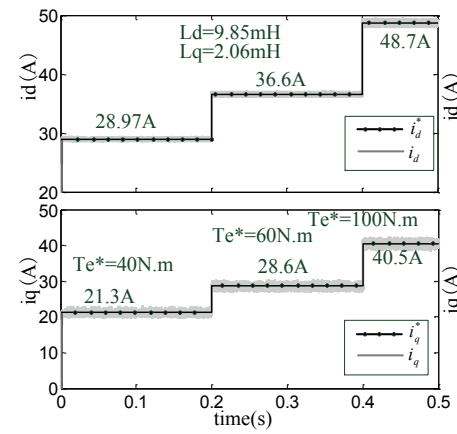

(a)

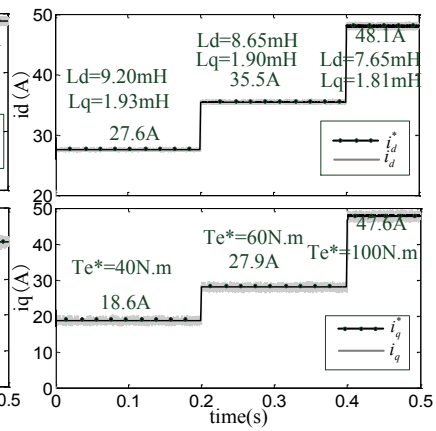

(b)
Fig. 9 the simulation result for torque change (a) without consideration of magnetic saturation (b) with consideration of magnetic saturation

In order to investigate the magnetic saturation influence on the trajectory offset of MTPA curve, the torque experiment is carried out with a constant speed of 500rpm in the simulation experiments, as shown in Fig. 9 (a) and Fig. 9 (b). The current reference value is black dotted line and the current feedback value is gray solid line. The simulation time is $0.5 \mathrm{~s}$ and the initial given torque is set to be $40 \mathrm{Nm}$, jumps to $60 \mathrm{Nm}$ at $0.2 \mathrm{~s}$, and jumps to $100 \mathrm{Nm}$ at $0.4 \mathrm{~s}$. Seen from the Fig.9 (a), the MTPA control algorithm ignores the saturation characteristics, the direct-axis inductance and the quadratureaxis inductance use the constant parameters of $9.85 \mathrm{mH}$ and $2.06 \mathrm{mH}$. At the same operating condition, the magnetic saturation is taken into consideration, as shown in Fig. 9 (b). Comparing Figs. 9 (a) and (b), when the torque is smaller than $40 \mathrm{Nm}$, at low current loading the phenomenon of magnetic saturation is not obvious. The d-axis inductance decreases $6.6 \%$ and the $\mathrm{q}$-axis inductance decreases $6.3 \%$, the $\mathrm{d}$-axis current setpoint error is $1.37 \mathrm{~A}$ and the q-axis current setpoint error is $1.37 \mathrm{~A}$. In the $0.2 \mathrm{~s}-0.4 \mathrm{~s}$ interval, the $\mathrm{d}$-axis inductance drops by $12.2 \%$ and the q-axis inductance decreases $7.8 \%$. Due to the magnetic saturation of the inductance, the deviation of the d-axis current reference value is $1.1 \mathrm{~A}$ and the q-axis current deviation value is $0.7 \mathrm{~A}$. For higher loading, with torque values around $100 \mathrm{Nm}$, the d-axis inductance decreases $22.3 \%$, the q-axis inductance decreases 
$12.1 \%$, the magnetic saturation is more significant, the d-axis current deviation is $0.6 \mathrm{~A}$ and the q-axis current deviation is 7.1A.

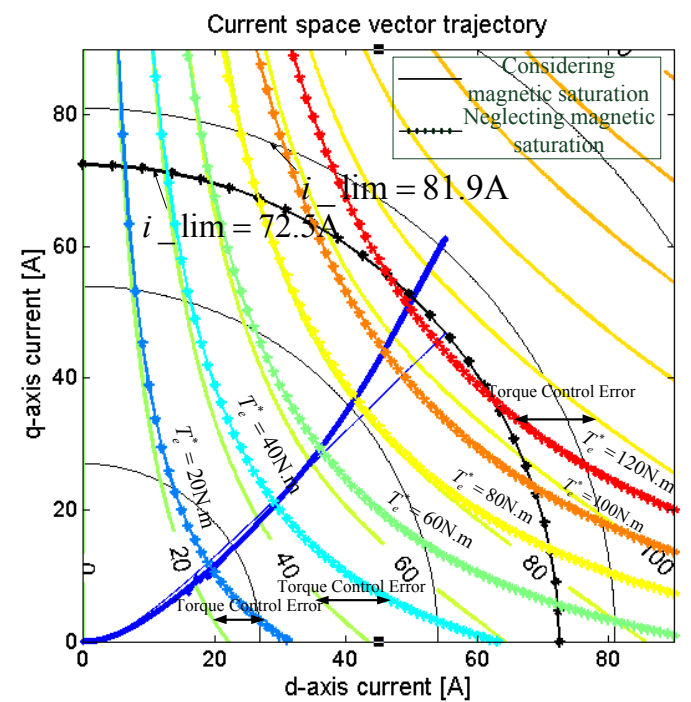

Fig. 10 the simulation result for torque change in dq current plane

If the response current considering magnetic saturation is drawn in the dq-axis current plane, as depicted in Fig. 10, the MTPA curves ignoring magnetic saturation are shown in blue thin lines and the actual MTPA curves are shown in blue thick line. The torque curve with and without the consideration of magnetic saturation are depicted with colored solid lines and the dotted lines, respectively. If the torque reference is set to be below $60 \mathrm{Nm}$, the MTPA curve deviation due to magnetic saturation is small. When the torque reference value increases above $60 \mathrm{Nm}$, or the load torque increases beyond $60 \mathrm{Nm}$, it can be noted that the MTPA curve is considerably shifted due to magnetic saturation, leading to higher copper loss.

\section{CONCLUSION}

In this paper, the influence of the magnetic saturation and cross saturation on the current setpoint of MTPA is analyzed in detail. The magnetic saturation effect leads the actual current trajectory to deviate from the optimal one, resulting in higher copper loss and lower efficiency. An automatic searching method second order Newton Raphson has been proposed and implemented to derive rapidly the current setpoint in the dq-axis current plane, involving just a few iterations (less than seven). The proposed method is novel and can be applied to any operating condition. Its fast convergence is practically useful when the motor is working under frequent change of the operating point. The parameters variation is considered and thanks to the Newton Raphson searching method it is possible to reduce the complexity and computational burden caused by the nonlinear functions. The FE simulations results and the validating tests are showing that the robustness is increased, and the current response is more rapid. The proposed solution can improve the accuracy of MTPA control for PMaSynRM.

\section{REFERENCES}

[1] Huynh T A, Hsieh M F. "Comparative study of PM-assisted SynRM and IPMSM on constant power speed range for EV applications,". IEEE Trans. on Magn. vol. 53, no.11, pp. 1-6, Apr. 2017.

[2] Guglielmi P, Boazzo B, Armando E. "Permanent-magnet minimization in PM-assisted synchronous reluctance motors for wide speed range, " [J]. IEEE Trans. Ind. Appl.,vol. 49, no. 1, pp. 31-41,Nov. 2013.

[3] Bianchi N, Mahmoud H, Bolognani S. "Fast synthesis of permanent magnet assisted synchronous reluctance motors". IET Electric Power Applications, vol. 10, no.5, pp.312-318. Jun. 2016

[4] Cai H, Guan B, Xu L. "Low-cost ferrite PM-assisted synchronous reluctance machine for electric vehicles" IEEE Trans. Ind. Electron., vol. 61, no.10, pp.5741-5748. Feb .2014

[5] Zhao J, Liu W, Tan B. "Research of maximum ratio of torque to current control method for PMSM based on least square support vector machines", IEEE Int. Conf. on Electrical and Control Engineering (ICECE), pp. 1623-1628.2010.

[6] X. Liu, H. Chen, J. Zhao, and A. Belahcen, "Research on the performances and parameters of interior PMSM used for electric vehicles," IEEE Trans. Ind. Electron., vol. 63, no. 6, pp. 3533-3545, Feb. 2016.

[7] Jo C, Seol J Y, Ha I J. "Flux-weakening control of IPM motors with significant effect of magnetic saturation and stator resistance". IEEE Trans. Ind. Electron. vol. 55, no. 3, pp. 1330-1340. Mar. 2008

[8] Rabiei A, Thiringer T, Alatalo M.. "Improved maximum-torque-perampere algorithm accounting for core saturation, cross-coupling effect, and temperature for a PMSM intended for vehicular applications". IEEE Trans. Transp. Electr. vol.2, no.2, pp 150-159. Feb. 2016

[9] Bolognani S, Petrella R, Prearo A. "Automatic tracking of MTPA trajectory in IPM motor drives based on AC current injection". IEEE Trans. Ind. Appl. vol. 47, no. 1, pp.105-114. Nov.2011

[10] Liu G, Wang J, Zhao W. "A Novel MTPA Control Strategy for IPMSM Drives by Space Vector Signal Injection". IEEE Trans. Ind. Electron. vol. 64, no. 12, pp.9243-9252. Jun.2017

[11] Lai C, Feng G, Mukherjee K. "Maximum Torque per Ampere Control for IPMSM Using Gradient Descent Algorithm based on Measured Speed Harmonics". IEEE Trans. Ind. Informatics, vol. 14, no. 4 pp. $1424-1435$.Oct.2017.

[12] Itoh J, Toi T, Kato M. "Maximum torque per ampere control using hill climbing method without motor parameters based on V/f control", in Proc. 2016 18th European Conf. on Power Electronics and Applications (EPE'16 ECCE Europe): pp. 1-10.

[13] Lemmens J, Vanassche P, Driesen J. "PMSM drive current and voltage limiting as a constraint optimal control problem". IEEE Journal Emerging and Selected Topics in Power Electronics, vol.3, no.2, pp. 326-338. Apr.2015

[14] Miao Y, Ge H, Preindl M. "MTPA Fitting and Torque Estimation Technique Based on a New Flux-Linkage Model for InteriorPermanent-Magnet Synchronous Machines". IEEE Trans. Ind. Appl., vol. 53, no.6, pp.5451-5460. July, 2017.

[15] K. Liu, Q. Zhang, J. Chen, Z. Zhu, and J. Zhang, "Online multiparameter estimation of non-salient-pole pm synchronous machines with temperature variation tracking, " IEEE Trans. Ind. Electron., vol.58, no. 5, pp. 1776-1788, 2011.

\section{BIOGRAPHIES}

Shuo Wang was born in Hebei, China, in 1988.He received the B.E. degree and the M.S. degree from Hebei university of Technology in 2011 and Tianjin University in 2014, respectively, and he is currently working toward the Ph.D. degree from Tongji University, Shanghai.

From 2017, he becomes a visiting Ph.D student in the Power Electronics, Machines and Control Group (PEMC) at the university of Nottingham.UK. His current research interests include high performance electrical machine drives, flux-weakening control strategy for EVs/HEVs, and precise torque control of PMSM and PMaSynRM.

Michele Degano (M'15) received the Laurea degree in electrical engineering from the University of Trieste, Trieste, Italy, in 2011, and the Ph.D. degree in industrial engineering from the University of Padova, Padova, Italy, in 2015. 
During his doctoral studies, he cooperated with several local companies for the design of permanent-magnet machines. In 2015, he joined the Power Electronics, Machines and Control Group, The University of Nottingham, Nottingham, U.K., as a Research Fellow, where he is currently an Assistant Professor teaching advanced courses on electrical machines. His main research interests include design and optimization of permanent-magnet machines, reluctance and permanent-magnet-assisted synchronous reluctance motors through genetic optimization techniques, for automotive and aerospace applications, ranging from small to large power.

Jinsong Kang was born in Shanxi, China, in 1972. He received the B.E. degree from Shanghai Railway Institute, Shanghai, China, and the Ph.D. degree from Tongji University, Shanghai, in 1994 and 2003, respectively.

He became an Professor in the Department of Electrical Engineering, Tongii University, Shanghai, in 2011. He was a Visiting Professor at Ryerson University, Toronto, ON, Canada, in 2007. His main research interests include the field of power electronics and drive control, including high voltage $\mathrm{dc} / \mathrm{dc}$ converters, drive system applied in electric vehicles, traction systems and auxiliary power supply of mass transit vehicles, and renewable energy systems

Alessandro Galassini was born in Trieste, Italy, in 1987. He received the Master's degree in mechatronics engineering from the University of
Modena and Reggio Emilia, Modena, Italy, in 2012. He has completed the $\mathrm{PhD}$ degree in the Power Electronics, Machines and Control Group (PEMC) at the University of Nottingham in 2017 where he has since been employed as a Research Fellow. His research interests relate to control and power sharing of multi-three-phase electrical machines for increased fault tolerance and reliability levels.

Chris Gerada received the Ph.D. degree in numerical modeling of electrical machines from The University of Nottingham, Nottingham, U.K., in 2005. He was a Researcher with The University of Nottingham, working on high-performance electrical drives and on the design and modeling of electromagnetic actuators for aerospace applications.

Since 2006, he has been the Project Manager of the GE Aviation Strategic Partnership. In 2008, he was appointed as a Lecturer with the Department of Electrical Machines; in 2011, as an Associate Professor; and in 2013, as a Professor with The University of Nottingham. His research interests include the design and modeling of high-performance electric drives and machines. Dr. Gerada serves as an Associate Editor for the IEEE Transactions On Industry Applications and is the Chair of the IEEE Industrial Electronics Society Electrical Machines Committee. 